\title{
Analisis Kombinasi Produktivitas dan Durasi Alat Berat Proyek Perataan Tanah Area Lahan Parkir PT. Smelting, Tbk.
}

\author{
Siti Choiriyah., ST., MT ${ }^{1}$, Prodenciana Paula Dos Santos ${ }^{2}$ \\ ${ }^{1}$ Teknik Sipil, Fakultas Teknik Sipil dan Perencanaan, Institut Teknologi Adhitama Surabaya \\ 2 Teknik Sipil, Fakultas Teknik Sipil dan Perencanaan, Institut Teknologi Adhitama Surabaya \\ Email: ${ }^{1}$ siti.choiriyah@itats.ac.id, ${ }^{2}$ prodencianapaula@gmail.com
}

\begin{abstract}
This project located on the ground with different elevation and to start the project, it must be leveled as in the parking lot project at PT Smelting. Tbk. The equipment used are bulldozers, excavators, and dump trucks. The maximum equipment resources on the project make the productivity of heavy equipment not in accordance with field implementation. We are using descriptive method to solve the problem in this research. This method quiantitively analyze the productivity and duration of work individually and a combination of field and planning to be selected according to timeliness and cost. The results of the combination IV, 1 unit Komatsu D65 EX bulldozer, productivity 7444 $m 3$ / day, duration of 14 days and operating costs Rp 63,215,000, 1 unit Komatsu PC excavator 200 - 8 MO productivity 8385,88 m3/day, work duration 15 days, operational costs $R p$ 84,900,275.5 units of dump truck nino FM 260 productivity 94.52 m3/day, work duration 22 days and operational costs $R p$ 430,518,605 with a total work duration of 408 hours.
\end{abstract}

Keywords: Excavator, Productivity, Duration

\begin{abstract}
Abstrak
Proyek ini berdiri di atas tanah dengan ketinggian yang tidak sama untuk memulainya harus diratakan seperti pada proyek lahan parkir di PT Smelting, Tbk. Peralatan yang digunakan adalah alat bulldozer, excavator, dan dump truck. Sumberdaya alat yang barang maksimal pada proyek menjadikan produktivitas alat berat tidak sesuai denagan pelaksanaan lapangan. Pemecahan permasalahan dalam penilitian ini menggunakan metode diskriptif. Kuantitatif menagnilisis produktivitas dan durasi kerja secara individu dan kombinasi antara lapangan dan perencanaan untuk dipilih sesuai dengan ketepatan waktu dan biaya. Hasil penelitian Kombinasi IV, 1 unit bulldozer Komatsu D65 EX, produktivitas $7444 \mathrm{~m} 3$ / hari, durasi 14 hari dan biaya operasional Rp 63.215.000, 1 unit excavator Komatsu PC 200 - 8 MO produktivitas 8385,88 m3/hari, durasi kerja 15 hari, biaya operasional Rp 84.900.275,5 unit dump truck nino FM 260 produktivitas 94,52 m3/hari, durasi kerja 22 hari dan biaya operasional Rp 430.518,605 dengan total durasi kerja 408 jam.
\end{abstract}

Kata kunci: Excavator, Produktivitas, Durasi

\section{Pendahuluan}

PT. Smelting, Tbk dalam membangun area parkir menggunakan alat berat untuk mempermudah pekerjaannya. Alat berat adalah sumber daya vital pada proyek konstruksi [1]. Pemilihan alat berat yang tepat akan bisa dimanfaatkan secara optimal dengan mendapat durasi yang tepat serta biaya operasional yang memadai dan juga produktivitasnya [2].

Proyek area parkir ini pekerjaan tanah dimulai dengan perataan, dikarenakan elevasi tanah tidak rata. Untuk penentuan level tapak sama maka diperlukan alat berat bulldozer, excavator dan dump truck[3]. Pelaksanaan pertama adalah bulldozer untuk proses pemotongan gundulan sampai tapak yang dinginkan kemudian hasil yang dinginkan kemudian hasil akan diambil oleh excavator untuk ditaruh di atas dump truck[4][5].

Proses perataan tanah selesai diikuti proses analisis produktivitas, durasi serta biaya tiap individu alat berat. Produktivitas adalah rasio antara seluruh hasil dengan sumber daya yang ada [6]. Diikuti dengan perhitungan durasi dan biaya. Dari analisis individu dilanjutkan ke kombinasi dan 
dibandingkan antara pekerjaan riil lapangan dan perencanaan. Kombinasi alat berat adalah pemakaian alat berat lebih dari satu alat untuk penyelesaian suatu pekerjaan [7].

\section{Metode}

Alur proses analisis kombinasi alat berat seperti gambar 2. Dengan urutan pelaksanaan yang dimuali dengan topik yang didapat di proyek, tinajauan pustakadiikuti dengan pengumpulan data dilanjutkan analaisis terakhir dengan kesimpulan.

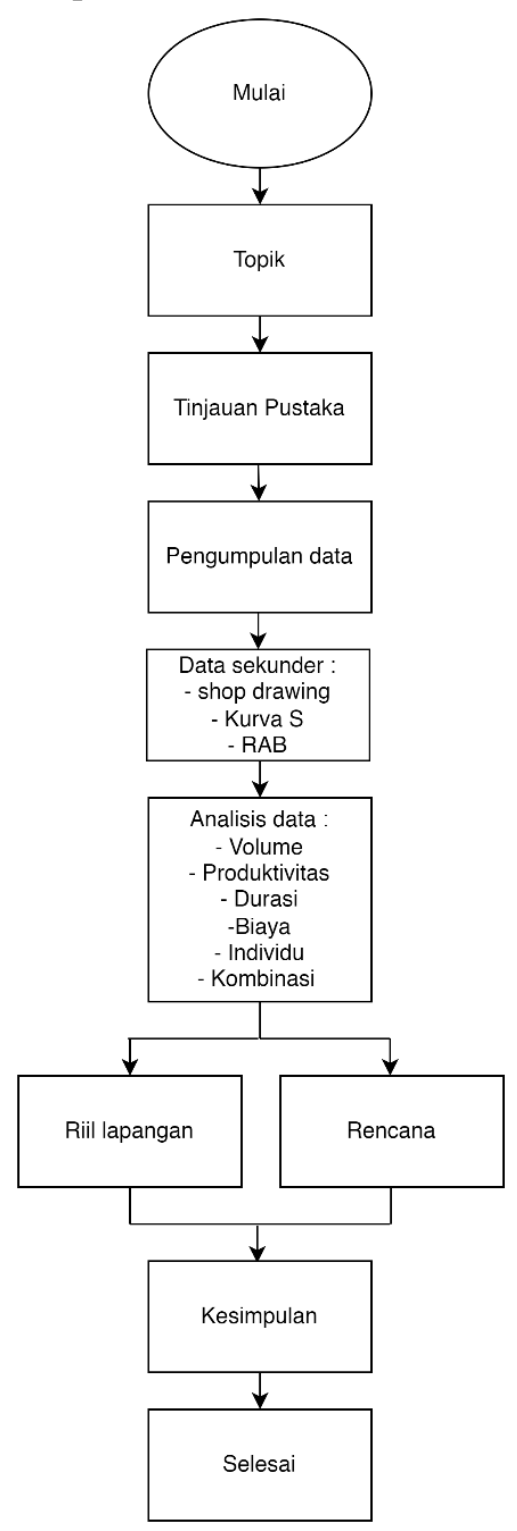

Gambar 1. Bagan alir analisis

\section{Hasil dan Pembahasan}

Dengan memperhitungkan faktor - faktor keadaan tanah, konversi tanah, sifat - sifat tanah, waktu siklus, effisiensi serta spesifikasi alat berat maka analisis dapat dilakukan

(1)Perhitungan volume 


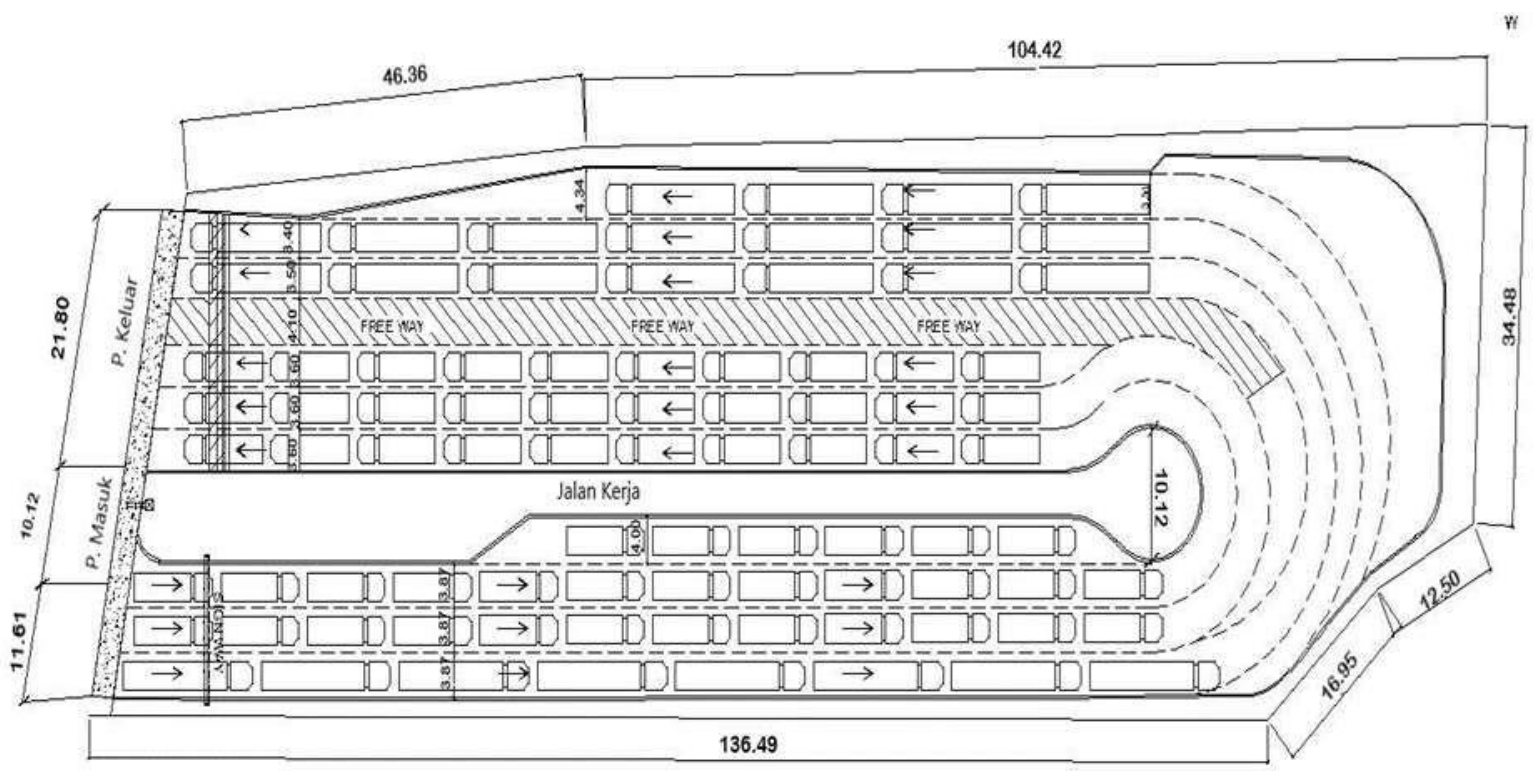

Gambar 2. Layout plan. Sumber: PT. Garuda Jaya Utama

$$
\begin{aligned}
& =136,49 \times 63,93 \times 2,37 \\
& =20632,1942 \mathrm{~m}^{3}
\end{aligned}
$$

$$
V=p x l \times t
$$

(2) Produktivitas Riil Lapangan

- Buldozer

- Spesifikasi: Komatsu D85 ESS - 2A

- jarak qusur 9I) $=50 \mathrm{~m}$

- Kapasitas blade $=3,4 \mathrm{~m}^{3}$

- Efisiensi Kerja $(\mathrm{F} 6)=0,75$

- faktor sudu (a) $=0,70$

- Tinggi sudu $(\mathrm{t})=1,30$

- Kecepatan maju $=4,7 \mathrm{~km} / \mathrm{jam}$

- V1 $=0,75$ x 4,7 km/jam $=59 \mathrm{~m} / \mathrm{menit}$

- Kecepatan mundur $=7,5$

- V2 $=0,85 \times 7,5 \mathrm{~km} / \mathrm{jam}=106,25 \mathrm{~m} / \mathrm{menit}$

- Waktu ganti persnelling 9z) $=0,20$ menit

- Waktu siktus (T)

$$
\begin{aligned}
V & =\frac{I}{V 1}+\frac{I}{V 2}+Z \\
& =\frac{50}{59}+\frac{50}{106,25}+0,20 \\
& =1,51 \text { menit }
\end{aligned}
$$

- Produksi per siklus:

$$
\begin{aligned}
& =3,40 \times(1,30)^{2} \times 0,7 \\
& =4,02 \mathrm{~m}^{3}
\end{aligned}
$$

- Produktivitas

$$
q=L x H^{2} x a
$$




$$
\begin{aligned}
& \qquad P=\frac{60 \times q \times F_{b}}{T} \\
& =\frac{60 \times 4,02 \times 0,75}{1,51} \times 1 \\
& =4,02 \mathrm{~m}^{3} \\
& \text { Perhari (jam kerja efektif 8jam/hari) } \\
& =1198 \times 8 \times 1,25 \\
& =9584 \mathrm{~m}^{3} / \text { hari }
\end{aligned}
$$

- Produktivitas perhari kondisi lepas

$Q=682,9 \times 8 \times 1,25$

$Q=5463,2 \mathrm{~m}^{3} /$ hari

- Unit excavator yang dibutuhkan

$$
\begin{aligned}
& N=\frac{Q \text { buldozer }}{Q \text { excavator }} \\
& N=\frac{1198}{5463,2} \\
& N=0,21=1 \text { unit }
\end{aligned}
$$

- Durasi excavator

$$
\begin{aligned}
\text { Durasi } & =\frac{\text { Vtotal }}{\text { Qexcavator }} \\
\text { Durasi } & =\frac{20632,1942 \mathrm{~m}^{3}}{5463,2 \mathrm{~m}^{3} / \text { hari }} \\
\text { Durasi } & =18 \text { hari } x 8 \text { jam efektif } \\
\text { Durasi } & =144 \text { jam }
\end{aligned}
$$

- Dump Truck

- Spesifikasi : Hino FM 260 JD

- Kapasitas (Cd): $24 \mathrm{~m}^{3}$

- Faktor bucket $(\mathrm{K})=0,8$

- Effisiensi alat $=0,8$

- Jarak buang $=12 \mathrm{~km}$

- V1 $($ bermuatan $)=18 \mathrm{~km} / \mathrm{jam}=300 \mathrm{~m} / \mathrm{menit}$

- V2 (kosong) $=30 \mathrm{~km} / \mathrm{jam}=500 \mathrm{~m} / \mathrm{menit}$

- Siklus pengisian Dump Truck

$$
\begin{aligned}
& N=\frac{C d}{V \times F b} \\
& N=\frac{24}{0,78 \times 1,1}=28 \text { siklus }
\end{aligned}
$$

- Waktu Siklus

- $\quad$ Muat (T1) $=\mathrm{Nx}$ Ts

$$
\text { Muat }(\mathrm{T} 1)=\frac{28 \times 34}{60}=16 \text { menit }
$$

- $\quad$ Buang $(\mathrm{Th})=\frac{\mathrm{D}}{\mathrm{V} 1} \times 60$

$$
\text { Buang }(\mathrm{Th})=\frac{12}{18} \times 60=40 \text { menit }
$$

- $\quad$ Kembali $(\mathrm{Tr})=\frac{\mathrm{D}}{\mathrm{V} 2} \times 60$

$$
\text { Kembali }(\mathrm{Tr})=\frac{12}{30} \times 60=24 \text { menit }
$$

- Ambil posisi $(\mathrm{Td})=1$ menit 
- $\quad$ Tunggu $(\mathrm{Tw})=6$ menit

Total waktu Siklus $(\mathrm{cm})=\mathrm{T} 1+\mathrm{Th}+\mathrm{Tr}+\mathrm{Td}+\mathrm{Tw}$

Total waktu Siklus $(\mathrm{cm})=18+40+24+1+6$

Total waktu Siklus $(\mathrm{cm})=89$ menit

- Produktivitas per siklus

$$
\begin{aligned}
& C=\text { Cd xk } \\
& C=24 \times 0,8=19,2 \mathrm{~m}^{3}
\end{aligned}
$$

- Produktivitas perjam

$$
\begin{aligned}
& \mathrm{C}=\frac{C \times 60 \times E}{C r} \\
& \mathrm{C}=\frac{19,2 \times 60 \times 0,80}{89} \\
& \mathrm{C}=10,35 \mathrm{~m}^{3} / \mathrm{km}
\end{aligned}
$$

- Produktivitas perhari

$$
\begin{aligned}
& Q=10,35 \times 8 \\
& Q=94,52
\end{aligned}
$$

- Jumlah dump truck

$$
\begin{aligned}
& \mathrm{C}=\frac{\text { Qexcavator }}{\text { Q dump truck }} \\
& \mathrm{C}=\frac{5463,2 \mathrm{~m}^{3} / \text { hari }}{94,52 \mathrm{~m}^{3} / \text { hari }} \\
& \mathrm{C}=5,1=5 \text { unit }
\end{aligned}
$$

- Durasi

$$
\begin{aligned}
& \text { Durasi }=\frac{\text { Vtotal }}{Q \text { dump truck }} \\
& \text { Durasi }=\frac{20632,1942 \mathrm{~m}^{3} / \text { hari }}{94,52 \mathrm{~m}^{3} / \text { hari }} \\
& \text { Durasi }=22 \text { hari } \\
& \text { Durasi }=22 \times 8=176 \mathrm{jam} \\
& \text { Durasi } 1 \text { unit }=176 / 5=35 \mathrm{jam}
\end{aligned}
$$

Dari analisis pekerjaan riil lapangan didapatkan hasil pada tabel 1

Tabel 1. Produktivitas dan Durasi Riil Lapangan Perhari

\begin{tabular}{cccccc}
\hline No & Pekerjaan & Alat Berat & Produktivitas & Durasi & Predecessor \\
\hline 1 & Perataan & Buldozer & 9584 & 17 & - \\
2 & Pengisian & Excavator & 5463,2 & 18 & $255+3$ days \\
3 & Pengangkutan & Dump truck & 94,52 & 22 & 355
\end{tabular}

\begin{tabular}{l} 
No $\mid$\begin{tabular}{l} 
Jenis pekerjaan \\
\hline
\end{tabular} \\
\hline
\end{tabular}

\section{Gambar 2 Grafik durasi kerja alat berat di lapangan.}

2) Produktivitas alat berat berdasarkan perencanaan dengan spesifikasi Alat Berat Berbeda

- Buldozer: Komatsu D65 Ex didapatkan

Produktivitas perhari $=7444 \mathrm{~m}^{3} /$ hari 
Durasi kerja $=112$ jam

Jumlah= 1 unit

- Excavator Komatsu PC 200-8 MO

Produktivitas perhari $=8385,88 \mathrm{~m}^{3} /$ hari

Jumlah $=1$ unit

Durasi kerja $=15$ hari

- Dump Truck Mitsubishi Fuso 220 PS

Produktivitas $=76,8 \mathrm{~m}^{3} / \mathrm{jam}$

Jumlah $=10$ unit

Durasi $=120 \mathrm{jam}$

1 unit $=12$ jam

Tabel 2. Produktivitas dan Durasi Rencana Perhari

\begin{tabular}{cccccc}
\hline Alat Berat & Tipe & Jumlah & Durasi & Prodecessor & Produktivitas \\
\hline Buldozer & Komatsu D65 Ex & 1 & 14 & - & \\
Excavator & Komatsu DC 200- & 1 & 15 & $255+3$ days & \\
8MO & Mitsubishi Fuso 220 & 10 & 15 & 355
\end{tabular}

Tabel 3. Time line alat berat perencanaan

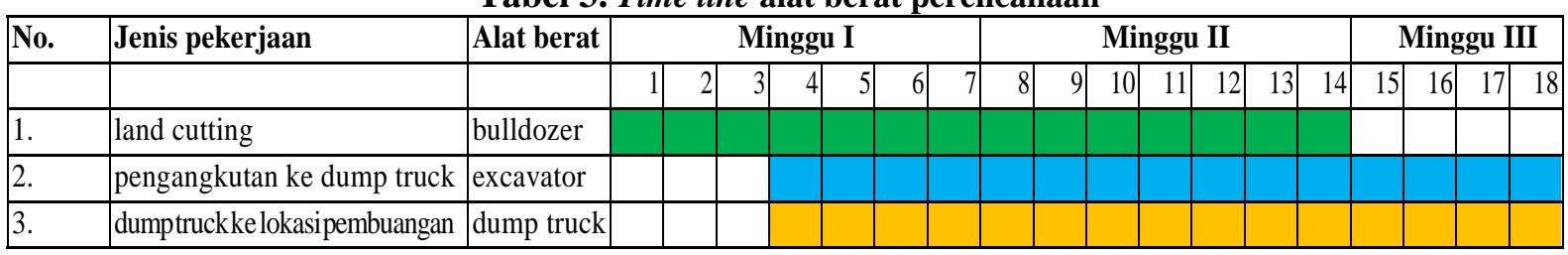



\section{Gambar 3. Grafik durasi kerja alat berat berdasarkan perencanaan}

3) Kombinasi alat berat

Analisis rasio antara pekerjaan lapangan dan perencanaan dikombinasiuntuk mendapat hasil durasi yang minimum dengan produktivitas maximum. 
Tabel 4. Kombinasi alat berat

\begin{tabular}{|c|c|c|c|c|c|c|c|}
\hline Tipe Alat & $\begin{array}{c}\text { Jumlah } \\
\text { alat } \\
\text { (unit) }\end{array}$ & $\begin{array}{c}\text { Produktivitas/ } \\
\text { jam } \\
\left(\mathbf{m}^{3} / \text { jam }\right)\end{array}$ & $\begin{array}{c}\text { Produktivitas/ } \\
\text { hari } \\
\left(\mathbf{m}^{3} / \text { hari }\right)\end{array}$ & $\begin{array}{l}\text { Durasi } \\
\text { kerja } \\
\text { (hari) }\end{array}$ & $\begin{array}{c}\text { Total durasi } \\
\text { kerja } \\
\text { (Jam) }\end{array}$ & \begin{tabular}{|c|} 
Biaya \\
Operasional Alat \\
Berat \\
(Rp)
\end{tabular} & $\begin{array}{c}\text { Total biaya } \\
\text { operasional } \\
\text { Alat Berat } \\
\text { (Rp) }\end{array}$ \\
\hline \multicolumn{8}{|c|}{ KOMBINASI I } \\
\hline \begin{tabular}{|l|} 
Bulldozer \\
komatsu D85ESS- \\
$2 \mathrm{~A}$
\end{tabular} & 1 & 1198 & 9584 & $\begin{array}{c}17 \\
(136 \mathrm{jam})\end{array}$ & \multirow{3}{*}{$432 \mathrm{jam}$} & 86.751 .069 & \multirow{3}{*}{454.054 .674} \\
\hline \begin{tabular}{|l|} 
Excavator \\
komatsu \\
PC200-8M0 \\
\end{tabular} & 1 & 1048,23 & 8385,88 & $\begin{array}{c}15 \\
(120 \mathrm{jam})\end{array}$ & & 84.900 .275 & \\
\hline \begin{tabular}{|l|} 
Dump truck \\
Hino FM 260 JD \\
\end{tabular} & 5 & 10,35 & 94,52 & $\begin{array}{c}22 \\
(176 \text { jam })\end{array}$ & & 282.403 .330 & \\
\hline \multicolumn{8}{|c|}{ KOMBINASI II } \\
\hline $\begin{array}{l}\text { Bulldozer komatsu } \\
\text { D65 EX }\end{array}$ & 1 & 930,50 & 7444 & $\begin{array}{c}14 \\
(112 \mathrm{jam})\end{array}$ & \multirow{3}{*}{376 jam } & 63.215 .000 & \multirow{3}{*}{689.874 .466} \\
\hline \begin{tabular}{|l|} 
Excavator \\
Komatsu PC130-8
\end{tabular} & 1 & 682,9 & 5463,2 & $\begin{array}{c}18 \\
(144 \mathrm{jam})\end{array}$ & & 229.301 .516 & \\
\hline \begin{tabular}{|l|} 
Dump truck \\
Mitsubishi \\
Fuso 220 PS \\
\end{tabular} & 10 & 9,6 & 76,8 & $\begin{array}{c}15 \\
(120 \mathrm{jam})\end{array}$ & & 397.357 .950 & \\
\hline \multicolumn{8}{|c|}{ KOMBINASI III } \\
\hline $\begin{array}{l}\text { Bulldozer } \\
\text { komatsu D85ESS- } \\
2 \mathrm{~A}\end{array}$ & 1 & 1198 & 9584 & $\begin{array}{c}17 \\
(136 \mathrm{jam})\end{array}$ & \multirow{3}{*}{$400 \mathrm{jam}$} & 86.751 .069 & \multirow{3}{*}{713.410 .535} \\
\hline $\begin{array}{l}\text { Excavator } \\
\text { Komatsu PC130-8 }\end{array}$ & 1 & 682,9 & 5463,2 & $\begin{array}{c}18 \\
(144 \mathrm{jam})\end{array}$ & & 229.301 .516 & \\
\hline \begin{tabular}{l|} 
Dump truck \\
Mitsubishi \\
Fuso 220 PS
\end{tabular} & 10 & 9,6 & 76,8 & $\begin{array}{c}15 \\
(120 \mathrm{jam})\end{array}$ & & 397.357 .950 & \\
\hline \multicolumn{8}{|c|}{ KOMBINASI IV } \\
\hline $\begin{array}{l}\text { Bulldozer komatsu } \\
\text { D65 EX }\end{array}$ & 1 & 930,50 & 7444 & $\begin{array}{c}14 \\
(112 \mathrm{jam})\end{array}$ & \multirow{3}{*}{408 jam } & 63.215 .000 & \multirow{3}{*}{430.518 .605} \\
\hline $\begin{array}{l}\text { Excavator } \\
\text { komatsu } \\
\text { PC200-8M0 }\end{array}$ & 1 & 1048,23 & 8385,88 & $\begin{array}{c}15 \\
(120 \mathrm{jam})\end{array}$ & & 84.900 .275 & \\
\hline $\begin{array}{l}\text { Dump truck } \\
\text { Hino FM } 260 \text { JD }\end{array}$ & 5 & 10,35 & 94,52 & $\begin{array}{c}22 \\
(176 \mathrm{jam})\end{array}$ & & 282.403 .330 & \\
\hline
\end{tabular}



Gambar 4. Perbandingan kombinasi alat berat. 


\section{Kesimpulan}

Kombinasi alat berat pada proyek lahan parkir PT. Smelting Tbk dipiliah kombinasi IV dari segi produktivitas dan durasi dengan 1 unit bulldozer Komatsu D65 EX produktivitas $7444 \mathrm{~m}^{3} /$ hari dengan durasi 14 hari kerja, 1 unit excavator Komatsu DC 200-8MO produktivitas 8385,88 $\mathrm{m}^{3} /$ hari dengan durasi 15 hari kerja, 5-unit dumptruck HinoFM260 1D produktivitas $94.52 \mathrm{~m}^{3} /$ hari durasi kerja 22 hari.

\section{Referensi}

[1] D. D. Gransberg and J. A. Rueda-Benavides, "Estimating Construction Equipment Productivity," Constr. Equip. Manag. Eng. Estim. Owners, no. July, pp. 111-136, 2020, doi: 10.1201/9780429186356-5.

[2] “ANALISA PERHITUNGAN PRODUKTIVITAS ALAT BERAT PADA PELAKSANAAN PEMATANGAN LAHAN UNTUK PEMBUATAN WORK SHOP DI KAB - PDF Download Gratis.pdf." .

[3] E. Handayani, M. Nuklirullah, and A. Riyadi, "Analisa Koefisien Harga Satuan Tenaga Kerja di Lapangan Dengan Analisa SNI Struktur Bangunan Gedung di Kota Jambi," J. Talent. Sipil, vol. 4, no. 1, p. 23, 2021, doi: 10.33087/talentasipil.v4i1.45.

[4] R. S. Alifen et al., "Analisa What If Sebagai Metode Antisipasi Keterlambatan Durasi Proyek," Civ. Eng. Dimens., vol. 1, no. 2, pp. 103-113, 1999.

[5] P. Ane, K. Pratasis, R. Masalah, and P. Masalah, "Kelayakan Investasi Studi Kasus Alat Berat Bulldozer, Excavator dan Dump Truck di Kota Manado," Sipil Statik, vol. 4, no. 9, pp. 533-539, 2016, [Online]. Available: https://ejournal.unsrat.ac.id/index.php/jss/article/view/13439.

[6] D. Roshindra, "Analisis Kombinasi Alat Berat Excavator Dan Dump," no. February, 2019.

[7] F. Teknik, J. Sipil, U. Sam, and R. Manado, "Manajemen alat berat pada pekerjaan bendungan lolak," vol. 8, no. 5, 2020. 